\title{
Carbide-Free Bainite: Compromise between Rate of Transformation and Properties
}

\author{
SANGEETA KHARE, KYOOYOUNG LEE, and H.K.D.H. BHADESHIA \\ By identifying the relationship between the time required to obtain bainite and parameters such \\ as the transformation temperature and carbon concentration, it has been possible to institute a \\ design procedure that led to the desired mechanical properties and transformation character- \\ istics. The work has also identified difficulties in the calculation of tensile elongation on the basis \\ of a percolation model, which suggests that fracture occurs when the fraction of austenite drops \\ below the percolation threshold in the microstructure.
}

DOI: $10.1007 / \mathrm{s} 11661-009-0164-\mathrm{z}$

(C) The Minerals, Metals \& Materials Society and ASM International 2010

\section{INTRODUCTION}

STRONG steels based on tempered martensitic microstructures continue to serve well in situations requiring a good combination of strength and toughness. ${ }^{[1-5]}$ Bainitic steels in this category have not in the past been competitive even though they have the potential of achieving the final structure by continuous cooling transformation, primarily because of the uncontrolled presence of cementite particles. The problem was not resolved by suppressing cementite precipitation using solutes such as silicon, until the realization that the thermodynamic limit to the extent of transformation that can be achieved also needed to be engineered during alloy design. ${ }^{[6,7]}$ This latter effect helps avoid large residues of untransformed austenite, which can then go on to produce martensite, which cracks. ${ }^{[6-8]}$

Excluding the transformation induced plasticity (TRIP)-assisted steels where the dominant phase is allotriomorphic ferrite, ${ }^{[9-13]}$ there are therefore two classes of strong steels that have been developed based on a microstructure consisting of bainitic ferrite, carbon-enriched retained austenite, and perhaps some martensite. The first consists of steels whose properties are achieved by continuous cooling transformation. ${ }^{[14-21]}$ The second is where the hardenability is controlled so that the transformation temperature is dramatically suppressed, giving slender plates of bainitic ferrite, under isothermal conditions. ${ }^{.22-31]}$ The transformation time in the latter case, however, can be greater than 10 days at temperatures as low as $125^{\circ} \mathrm{C}$, making the process suitable for large components; strength values in excess of $2000 \mathrm{MPa}$ can routinely be achieved.

SANGEETA KHARE, Researcher, and H.K.D.H. BHADESHIA, Director and Professor, are with the Graduate Institute of Ferrous Technology (GIFT), Pohang University of Science and Technology (POSTECH), Pohang 790-784, Republic of Korea. Contact e-mail: skhare@postech.ac.kr KYOOYOUNG LEE, Senior Researcher, is with the Automotive Steel Products Research Group, Technical Research Laboratories, POSCO, Jeonnam 545-090, Republic of Korea.

Manuscript submitted March 16, 2009.

Article published online February 6, 2010
There is an industrial requirement for the mass production of strong steel sheet a few millimeters thick using a continuous process that is rapid and in which the transformation must occur over a narrow temperature range around $350{ }^{\circ} \mathrm{C}$, making the process essentially isothermal. The transformation temperature is fixed by the production process and the transformation time must be limited to 10 minutes. The ultimate tensile strength should be approximately $1400 \mathrm{MPa}$ with a ductility of about 20 pct. The purpose of the present work was to see if such a steel can be achieved based on the carbide-free bainitic microstructure described previously.

\section{FEASIBILITY}

The short isothermal transformation time is the vital design criterion, and to assess whether this can be achieved, data were collected from reported isothermal transformation experiments on carbide-free bainite. ${ }^{[7,22,32-34]}$ The data are plotted in Figure 1. They correspond to a variety of silicon-rich steels with the carbide-free bainite; much of the variation in the transformation temperature is due to differences in the carbon concentrations of the alloys. The transformation time increases dramatically as the carbon suppresses the transformation temperature. The curves in Figure 1 are generated by subjecting the data to neural network analysis, ${ }^{[35,36]}$ and the upper and lower curves in each plot represent $\pm 1 \sigma$ modeling uncertainties. Note that the limited data do not deter from using a neural network based on a Bayesian framework in order to identify and plot the uncertainty bounds illustrated. The Bayesian approach used ${ }^{[35,36]}$ avoids the overfitting, which may lead to a modeling of noise in the data.

The shortest time plotted in Figure 1 is 30 minutes, but the trend indicates that, by controlling the chemical composition, it should be feasible to design a steel to comply with the required 10 minutes in the temperature range of interest and to achieve the required strength. The elongation data show a great deal of scatter so a 


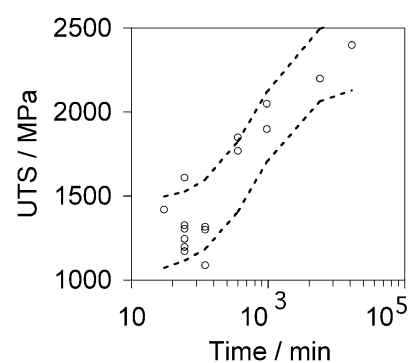

(a)

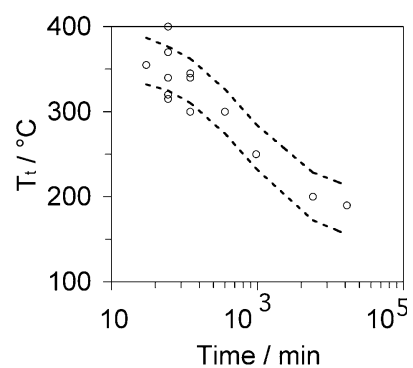

(b)

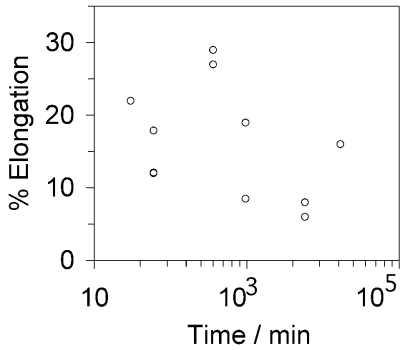

(c)

Fig. 1-Published experimental data (points) ${ }^{[7,22,32-34]}$ as a function of transformation time. The curves represent $\pm 1 \sigma$ confidence limits obtained by subjecting the data to a neural network analysis. (a) Ultimate tensile strength as a function of isothermal transformation time. (b) Transformation temperature $\left(T_{t}\right)$ as a function of isothermal transformation time. $(c)$ Elongation as a function of isothermal transformation time.

different procedure will be used to estimate the expected ductility.

\section{DESIGN}

The kinetics of transformation as a function of chemical composition were calculated using a method described elsewhere. ${ }^{[37-39]}$ In brief, a time-temperaturetransformation (TTT) diagram is modeled as consisting of two "C" curves, the one at higher temperatures representing the initiation of reconstructive transformations (allotriomorphic and idiomorphic ferrite, and pearlite) and the lower one, the formation of displacive transformation products such as Widmanstätten ferrite and bainite. The time period for the initiation of each transformation is calculated using equations based on Russell's incubation period theory, as described in Reference 37. The steel composition $(\mathrm{C}, \mathrm{Si}, \mathrm{Mn}, \mathrm{Ni}$, $\mathrm{Mo}, \mathrm{Cr}, \mathrm{V}, \mathrm{W}, \mathrm{Cu}$ ) enters into these equations via a free energy change during the nucleation of ferrite from austenite. The lower $\mathrm{C}$ curve has a flat top at a temperature $T_{h}$, which may correspond to the Widmanstätten ferrite start temperature or the bainite start temperature $\left(B_{S}\right)$, depending on the free energy available. ${ }^{40]}$ The martensite start temperature $\left(M_{S}\right)$ is also calculated thermodynamically, defined by the temperature at which the driving force for diffusionless transformation exceeds the critical value required to trigger nucleation. ${ }^{[38,39]}$ These calculations define the whole of the initiation part of the TTT diagram and have a reasonable reliability, which has been confirmed in a vast number of design experiments, including those covering wrought and welding materials based on iron. The computer programs for conducting these calculations are freely available at www.msm.cam.ac.uk/ map/mapmain.html. The primary role of the calculations in this work is to define the time period for the onset of the bainite reaction at the required isothermal transformation temperature.

An extensive set of TTT-curve calculations were carried out in which the composition was varied systematically in the range 0 to $1 \mathrm{Co}, 1$ to $2 \mathrm{Cr}, 1$ to $2.5 \mathrm{Ni}, 1.2$ to $2 \mathrm{Mn}, 0$ to $1 \mathrm{~W}$ wt pet. Silicon and aluminum were fixed at 1.5 and $0.5 \mathrm{wt}$ pct, respectively, in order to control cementite precipitation; aluminum, like cobalt, also helps accelerate the bainite reaction. ${ }^{[25,41]}$ Carbon has the largest influence in the suppressing transformation temperature, so its concentration must be kept low enough to be able to achieve the required rate of reaction, but high enough to ensure that the necessary level of strength is achieved. Its concentration, therefore, was fixed at $0.35 \mathrm{wt}$ pct, a value indicated by the data plotted in Figure 1, particularly the experiments reported in References 16 and 19, where the mechanical properties achieved are not far from what was required here, but using different heattreatment conditions. The molybdenum concentration was maintained at $0.25 \mathrm{wt}$ pct in order to prevent the embrittlement of austenite grain boundaries by impurities such as phosphorus. A small amount of vanadium (0.1 wt pct) was included for austenite grain size control.

The calculation starts by initializing elements as $\mathrm{Co}(1), \mathrm{Cr}(1), \mathrm{Ni}(2)$, and $\mathrm{Mn}(2)$, where the number in parentheses represents the element concentration in weight percent; these values are varied systematically in sequence of steps, while keeping other elements such as $\mathrm{C}, \mathrm{Si}, \mathrm{Mo}, \mathrm{Al}$, and $\mathrm{V}$ fixed, as described previously. Figure 2(a) is the calculated TTT diagram for composition [0-1]Co-1Cr-2Ni-2Mn, with Co varying between 0 and $1 \mathrm{wt}$ pet. The value $\mathrm{Co} \approx 1 \mathrm{wt}$ pct was found to accelerate the bainitic transformation and increase the bainitic range, i.e., the difference between $B_{S}$ and $M_{S}$ temperatures, and thus is used as the optimum value for the next step. Figure 2(b) represents the calculated TTT diagram for $1 \mathrm{Co}-[1-2] \mathrm{Cr}-2 \mathrm{Ni}-2 \mathrm{Mn}$ with $\mathrm{Cr}$ varying between 1 and 2 wt pct. The calculation showed that $\mathrm{Cr} \approx 1$ wt pet performs better as compared to $\mathrm{Cr} \approx$ 2 wt pct. Therefore, the starting composition for the next step in Figure 2(c) becomes $1 \mathrm{Co}-1 \mathrm{Cr}-[1-2.5] \mathrm{Ni}$ $2 \mathrm{Mn}$ with $\mathrm{Ni}$ concentration varying between 1 and $2.5 \mathrm{wt}$ pct. The value of $\mathrm{Ni} \approx 1 \mathrm{wt}$ pct was found to enhance bainite kinetics and also broadens the bainitic range. By fixing the starting composition to $1 \mathrm{Co}-1 \mathrm{Cr}$ $1 \mathrm{Ni}-[1.2-2] \mathrm{Mn}$ with $\mathrm{Mn}$ varying between 1.2 and $2.0 \mathrm{wt}$ pet and including tungsten (1 wt pct) in this step, a calculated TTT diagram was shown in Figure 2(d). The value of $\mathrm{Mn} \approx 1.2 \mathrm{wt}$ pct further improves the bainitic range and also substantially accelerates the initialization of bainite transformation to lower time.

The summary of the various steps in Figures 2(a) through (d) is presented in Figure 2(e), where curve " $A$ " represents the highest rate of transformation to bainite 


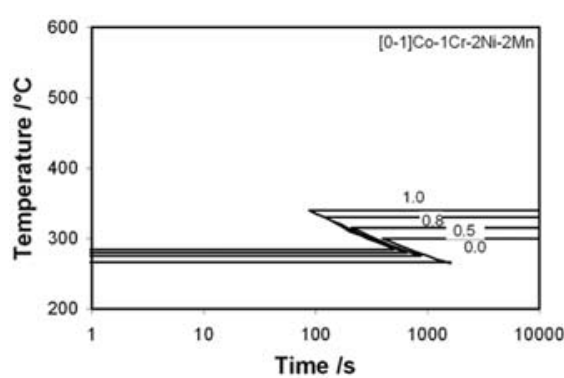

(a)



(d)

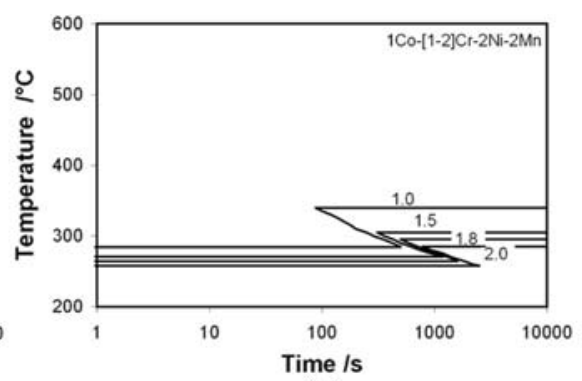

(b)

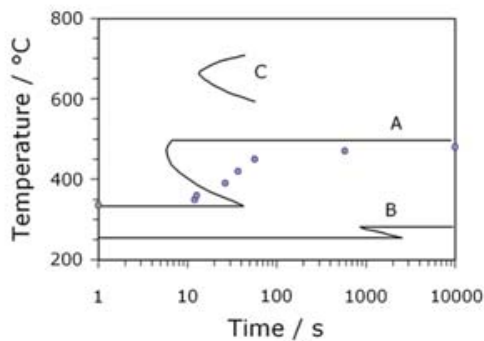

(e)

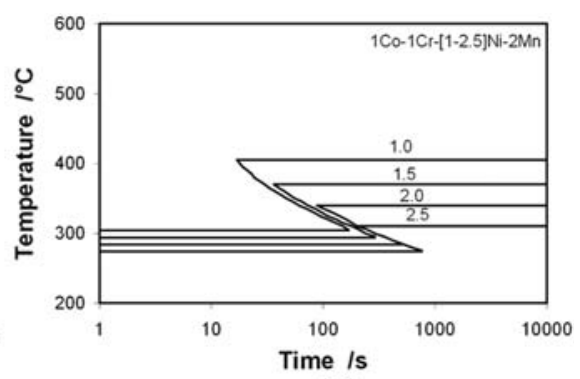

(c)

Fig. 2 - Calculated time-temperature-transformation curves for the initiation of transformation. (a) Effect of cobalt in alloy containing 1Cr-2Ni$2 \mathrm{Mn}$ wt pct. (b) Effect of chromium in alloy containing $1 \mathrm{Co}-2 \mathrm{Ni}-2 \mathrm{Mn}$ wt pct. (c) Effect of nickel in alloy containing $1 \mathrm{Co}-1 \mathrm{Cr}-2 \mathrm{Mn}$ wt pct. (d) Effect of manganese in alloy containing $1 \mathrm{Co}-1 \mathrm{Cr}-1 \mathrm{Ni}-1 \mathrm{~W}$ wt pct. (e) Curves "A" and "B" refer to the highest and lowest rates of bainite transformation, whereas " $\mathrm{C}$ " describes the formation of allotriomorphic ferrite. The points are the experimental data described later.

with composition $1 \mathrm{Co}-1 \mathrm{Cr}-1 \mathrm{Ni}-1.2 \mathrm{Mn}-1 \mathrm{~W}$ while curve " $\mathrm{B}$ " represents the lowest rate of transformation, having composition $1 \mathrm{Cr}-2 \mathrm{Ni}-2 \mathrm{Mn}$; all other alloys have calculated transformation curves that fall between these two limits. Given the temperature at which bainite is expected to form, the $M_{S}$ temperature of the alloy must be below $350^{\circ} \mathrm{C}$. Curve "A" represents the upper limit of the acceptable amount of alloying permitted to meet this criterion. Clearly, increasing the hardenability of austenite leads to the suppression of transformation temperatures and a reduction in the reaction rate, as indicated by curve " $\mathrm{B}$ ". The steel corresponding to curve " $A$ " was selected for further investigation; it has the chemical composition Fe-0.35C-1.5Si-0.5Al$0.25 \mathrm{Mo}-1.2 \mathrm{Mn}-1 \mathrm{Cr}-1 \mathrm{Ni}-0.1 \mathrm{~V}-1 \mathrm{Co}-1 \mathrm{~W}$ (wt pet).

For this alloy, the calculated initiation of the allotriomorphic ferrite reaction is indicated by curve " $\mathrm{C}$ " in Figure 2(e). It appears that the hardenability of this alloy is sufficient to avoid any elevated temperature transformation given that the steel sheet is expected to be cooled at a rate of $5{ }^{\circ} \mathrm{C} \mathrm{s}^{-1}$ in the critical temperature range $700{ }^{\circ} \mathrm{C}$ to $500{ }^{\circ} \mathrm{C}$. The calculated $M_{S}$ temperature is about $330{ }^{\circ} \mathrm{C}$.

Judging from Figure 1, the alloy should achieve the design strength, but it is necessary to estimate the expected elongation. It has been suggested that with microstructures of the kind considered here, failure in a tensile test occurs when the retained austenite loses continuity $^{[42]}$ and that this percolation threshold is reached when the austenite fraction reaches about 0.1 . The fraction of austenite present in the initial microstructure can be calculated from the fact that the bainite reaction, in the absence of cementite precipitation, obeys the incomplete reaction phenomenon. ${ }^{[43]}$ This happens when the carbon concentration in the residual austenite reaches the $T_{0}{ }^{\prime}$ curve, which represents the locus of all points on a plot of temperature vs carbon concentration, where austenite and ferrite of the same composition have identical free energies after allowing for the stored energy $\left(400 \mathrm{~J} \mathrm{~mol}^{-1}\right)$ of bainite. ${ }^{[40]}$ The austenite remaining at $350{ }^{\circ} \mathrm{C}$ at the cessation of the bainite reaction, $V_{\gamma}^{T}$, is given by

$$
V_{\gamma}^{T} \approx\left(x-x_{\alpha}\right) /\left(x_{T 0}-x_{\alpha}\right)
$$

where $x$ is the average carbon concentration, $x_{T 0}$ is the concentration corresponding to the $T_{0}$ curve, and $x_{\alpha}$ is the concentration in ferrite. Therefore, the residual austenite at $350{ }^{\circ} \mathrm{C}$ was calculated as $V_{\gamma}^{T}=0.33$. Some of this will decompose to martensite on cooling; the retained fraction $V_{\gamma}^{0}=0.24$ was calculated using the Koistinen and Marburger equation. ${ }^{[44]}$ The decomposition of the retained austenite as a function of plastic strain was then calculated using a published model, ${ }^{[45]}$ which has recently been shown to be the optimum method for such calculations. ${ }^{[46]}$ It is based on the equation

$$
\ln V_{\gamma}^{0}-\ln V_{\gamma}=k_{1} \Delta G^{\alpha^{\prime} \gamma} \mathrm{C}
$$

where $V_{\gamma}^{0}$ is the fraction of austenite before deformation, $V_{\gamma}$ the austenite content as a function of the plastic strain $\epsilon$, and $\Delta G^{\alpha^{\prime} \gamma}$ the chemical free energy change for transformation without a change in composition (calculated using MTDATA ${ }^{[47]}$ ). The constant $k_{1}$ has the value $0.002017 \mathrm{~mol} \mathrm{~J}^{-1}{ }^{[45]}$ Figure 3 shows that percolation is lost when the elongation is approximately 15 pct. 


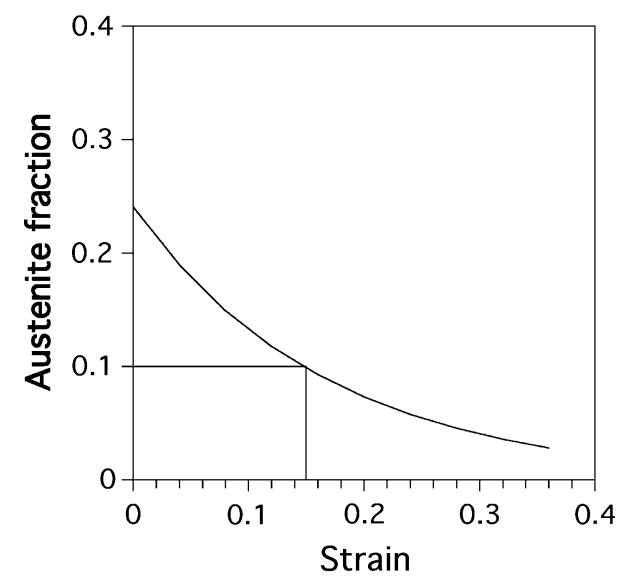

Fig. 3-Calculated decrease in retained austenite content as a function of plastic strain.

\section{EXPERIMENTAL DETAILS}

An alloy was made in a vacuum induction furnace; the ingot was reheated to $1200{ }^{\circ} \mathrm{C}$ for 1 hour followed by hot rolling into $30-\mathrm{mm}$ plate. The chemical composition of the resulting alloy is similar to the intended design: Fe-0.34C-1.47Si-0.54Al-0.24Mo-1.20Mn-0.95Cr$0.91 \mathrm{Ni}-0.10 \mathrm{~V}-1.04 \mathrm{Co}-0.99 \mathrm{~W}$ (wt pet). Cylindrical specimens of length $10 \mathrm{~mm}$ and diameter $5 \mathrm{~mm}$ were subjected to programmed heat treatments in the dilatometer (DIL805 BÄHR Thermoanalyse, Hüllhorst, Germany) described elsewhere. ${ }^{[48]}$

Tensile testing was conducted on flat samples based on ASTM-E8 geometry (1.5-mm thick, 6-mm wide, and 25-mm gage length) using a Zwick machine (Z600 Zwick Roell, Ulm, Germany) at a crosshead speed of $10 \mathrm{~mm}$ $\min ^{-1}$.

Retained austenite measurements were conducted using $\mathrm{Cu} K_{\alpha}$ X-ray diffraction and Reitveld analysis ${ }^{[49,50]}$ of the resulting data; the details have been described elsewhere. ${ }^{[30]}$

\section{RESULTS AND DISCUSSION}

The optical and transmission electron micrographs are presented in Figure 4; not surprisingly, the microstructure is a routine mixture of platelets of bainitic ferrite embedded in retained austenite.

The $M_{S}$ temperature of the steel was determined dilatometrically by austenitizing at $950{ }^{\circ} \mathrm{C}$ for 3 minutes followed by cooling at $20^{\circ} \mathrm{C} \mathrm{s}^{-1}$; the data illustrated in Figure 5 were analyzed using the offset method, ${ }^{[48]}$ in which the deviation that identifies the onset of transformation is fixed by calculating the strain corresponding to 1 pet martensitic transformation in the alloy of interest. From five experiments, $M_{S}$ was determined to be $336 \pm 10^{\circ} \mathrm{C}$, which is consistent with the value calculated in References 38 and 39 at $330{ }^{\circ} \mathrm{C}$, and indeed with the requirement to produce bainite by isothermal transformation at $350{ }^{\circ} \mathrm{C}$.

Figure 6(a) shows the corresponding dilatometric data for the isothermal formation of bainite; they show

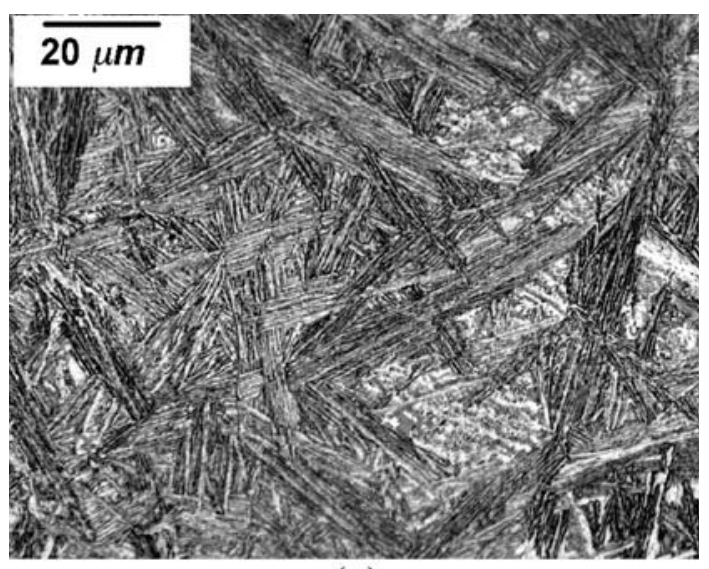

(a)

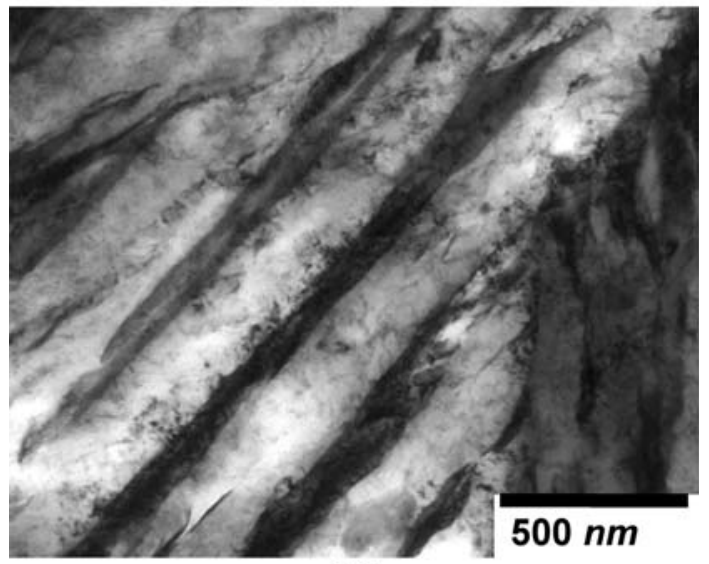

(b)

Fig. 4 - (a) Optical and (b) transmission electron micrograph structure obtained by isothermal transformation at $350{ }^{\circ} \mathrm{C}$ for $10 \mathrm{~min}$.

the expected incomplete reaction phenomenon, with the extent of transformation diminishing to zero as the temperature is raised toward the $B_{S}$ temperature. The maximum strain $(\epsilon)$ observed was converted into a volume fraction, as in Reference 51, so that the carbon concentration of the residual austenite could be determined. The points plotted in Figure 6(b) show that, as expected, the reaction ceases when carbon concentration in the austenite reaches the $T_{0}^{\prime}$ curve; the discrepancies at low transformation temperatures are expected from the fact that films of austenite trapped between platelets of bainite are able to accumulate more carbon without transforming. ${ }^{[52,53]}$

The data in Figure 6 were also used to compare the measured transformation kinetics against the calculated TTT diagram for the initiation of reaction, assuming that this corresponds to the formation of 0.01 volume fraction of bainite irrespective of the transformation temperature. Figure 2(e) shows that the calculations ${ }^{[37]}$ mostly underestimate the time required to form this fraction of bainite; the reason for this discrepancy is not clear.

Figure 7(a) shows plots of engineering stress $v s$ engineering strain for three tensile test samples; the recorded values of ultimate tensile strength and total elongation are found to be 1452 to $1457 \mathrm{MPa}$ and 12 to 


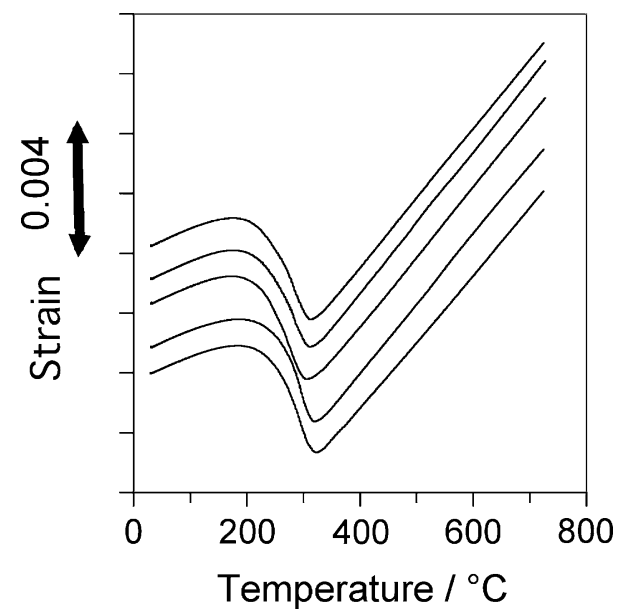

Fig. 5-Martensite start temperature measurements.

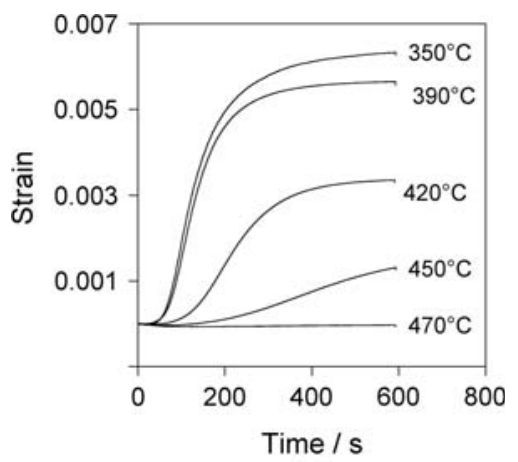

(a)



(b)

Fig. $6-(a)$ Isothermal transformation dilatometric curves. (b) Calculated $T_{0}^{\prime}, T_{0}$, and the paraequilibrium $A e^{\prime}{ }_{3}$ curve, together with experimental data (points) showing the carbon concentration at which the bainite reaction ceases.

15 pct, respectively, and the uniform elongation is 7 to 8 pct. The measured total elongation is close to that calculated using the percolation model at 15 pct in Figure 3. The calculation was based on $V_{\gamma}^{0}$ estimated to be 0.24 using Eq. [1]. The same equation using the experimental value of $x_{\gamma}$ (Figure 6(b)) rather than $x_{T 0}$

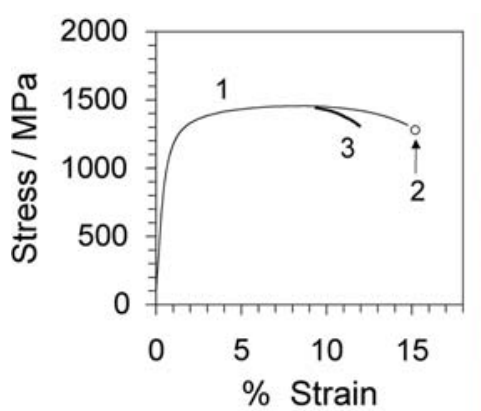

(a)

(b)

Fig. 7-(a) Three engineering stress $v s$ engineering strain curves. Curve 1 is plotted in full, and curve 2 is almost identical so only the final point corresponding to failure is plotted. (b) The tensile test sample after fracture.

yields $V_{\gamma}^{T}=0.22$, and since the $M_{S}$ temperature is suppressed to $-37^{\circ} \mathrm{C}, V_{\gamma}^{0}=V_{\gamma}^{T}$. Curve "a" in Figure 8 shows the consequent change in the strain-induced transformation behavior, indicating that the elongation to be expected should be 25 pct because of the increased thermodynamic stability of the austenite.

Curve "b" in Figure 8 is calculated using an X-ray diffraction determined value of $V_{\gamma}^{0}=0.17$; the diffraction experiment was repeated twice to confirm that the fraction of retained austenite is between 0.17 and 0.18 . With this, the predicted elongation at 16 pct is closer to the measured values in the range of 12 to 15 pct.

The carbon concentrations of the residual austenite in Figure 6(b) were derived from the corresponding dilatometric curves by converting the maximum observed dilatation at any temperature into a fraction of transformation and then, using mass balance, into $x_{\gamma}{ }^{[51]}$ This involves a calculation of the lattice parameters of the austenite and ferrite as a function of the solute concentration and temperature. For $350{ }^{\circ} \mathrm{C}$, the parameter for the carbon-enriched residual austenite at the point of maximum transformation strain was calculated to be $3.6512 \AA$, which is calculated using thermal expansivity measurements to contract to $3.6236 \AA$ at ambient temperature. The latter is reasonably consistent with the X-ray determined lattice parameter of the retained austenite at $3.6175 \pm 0.001 \AA$. This gives confidence in the interpretation of the dilatometrically determined $x_{\gamma}=1.47 \mathrm{wt}$ pct, which at most may be an overestimation by $0.18 \mathrm{wt}$ pct if the X-ray determined lattice parameter is used. If the X-ray measurement is taken to be more accurate, then the $M_{S}$ temperature of $V_{\gamma}^{T}$ would rise to $20^{\circ} \mathrm{C}$ so that martensite would not form on cooling the sample to room temperature; this does not strictly explain the discrepancy between the values of $V_{\gamma}^{0}$ for curves "a" and "b" illustrated in Figure 8. The explanation consistent with past experience ${ }^{[54]}$ is that the carbon is not uniformly distributed, with the larger 


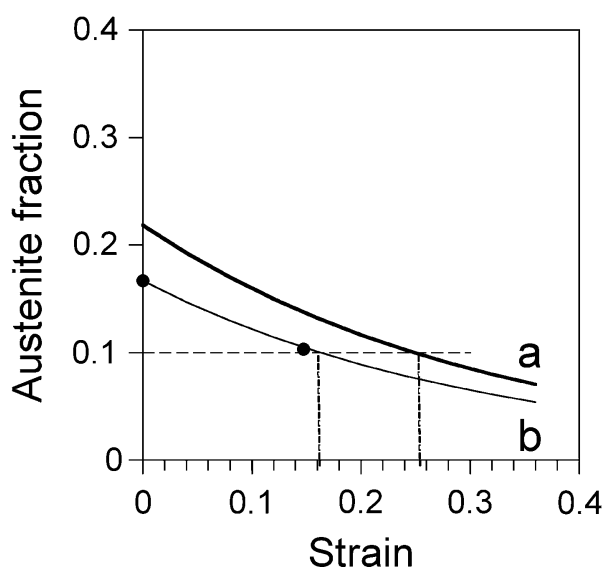

Fig. 8 - Calculations of strain-induced transformation of austenite assuming $(a)$ dilatometrically determined $V_{\gamma}^{0}=0.22$ and $(b)$ X-ray determined $V_{\gamma}^{0}=0.17$. The points correspond to measured values.

islands containing a lower concentration and hence decomposing to martensite on cooling.

It follows that one difficulty in calculating the fracture strain is the estimation of the fraction and stability of the austenite, given that the latter phase is unlikely to be homogeneous in terms of both size and carbon concentration. A second feature neglected in the percolation analysis is that the macroscopic strain will not, in the later stages of deformation, be uniform given the onset of necking in a tensile test. A further analysis was done to examine the consequences of the latter effect by comparing the local strain at the neck to the value measured over a gage length of $25 \mathrm{~mm}$. Figure 7(b) shows the fractured tensile specimen; there was virtually zero plastic strain in the $z$ direction with the failure typical of thin samples via shear on the plane containing $y$ and inclined at $45 \mathrm{deg}$ to $x$. The contraction strain along $y$ at the arrowed position of fracture was $\epsilon_{y}=$ -17 pct, which, because $\epsilon_{z}$ is zero, corresponds to an elongation along the tensile axis of $\epsilon_{x}=17$ pct, which is only slightly larger than the 15 pct recorded over the entire gage length ( $c f$. calculated value of $16 \mathrm{pct}$ ). Therefore, it is concluded that, in the present case, the necking does not significantly influence the outcome of the percolation analysis because of the thin-sheet shape of the specimen.

As a precautionary comment, it is worth emphasizing that the fracture strain as a generic issue depends not only on the occurrence of necking, but also on the damage sites and rate of occurrence. The austenite clearly has a role in determining ductility, but the relationship of ductility and the quantity of retained austenite generally cannot be straightforward.

\section{CONCLUSIONS}

By assessing the literature data on the relationship between transformation time and mechanical properties, it has been possible with the help of design procedure to obtain, in the first iteration, a steel that has the desired microstructure of carbide-free bainitic ferrite and carbon-enriched retained austenite. Furthermore, the structure can, as required, be obtained by isothermal transformation for 10 minutes and has been shown experimentally to have the intended properties.

The work has also identified detailed discrepancies in the calculation of time-temperature-transformation diagrams and in the estimation of elongation. These topics will be the subject of continued research.

\section{ACKNOWLEDGMENTS}

We are grateful to Professor Hae-Geon Lee, Graduate Institute of Ferrous Technology, for the provision of laboratory facilities at POSTECH, and to POSCO for help and support.

\section{REFERENCES}

1. M.J. May, T. Gladman, and E.F. Walker: Philos. Trans. R. Soc., London, 1976, vol. 282A, pp. 377-87.

2. W.M. Imrie: Philos. Trans. R. Soc., London, 1976, vol. 282A, pp. $91-104$.

3. W.M. Garrison, Jr.: J. Met., 1990, vol. 42, pp. 20-24.

4. Y. Tomita: Mater. Sci. Technol., 1991, vol. 7, pp. 481-89.

5. G. Luxenburger, M. Bockelmann, P. Wolf, F. Hanus, R. Cawelius, and J. Buchholz: Int. J. Press. Vess. Pip., 2004, vol. 81, pp. $159-71$.

6. H.K.D.H. Bhadeshia and D.V. Edmonds: Met. Sci., 1983, vol. 17, pp. 411-19.

7. H.K.D.H. Bhadeshia and D.V. Edmonds: Met. Sci., 1983, vol. 17, pp. $420-25$.

8. S. Chatterjee and H.K.D.H. Bhadeshia: Mater. Sci. Technol., 2006, vol. 22, pp. 645-49.

9. O. Matsumura, Y. Sakuma, and H. Takechi: Trans. Iron Steel Inst. Jpn., 1987, vol. 27, pp. 570-79.

10. O. Matsumura, Y. Sakuma, and H. Takechi: Scripta Metall., 1987, vol. 27, pp. 1301-06.

11. Y. Sakuma, O. Matsumura, and H. Takechi: Metall. Mater. Trans. A, 1991, vol. 22A, pp. 489-98.

12. P.J. Jacques: Curr. Opin. Solid State Mater. Sci., 2004, vol. 8, pp. 259-65.

13. B. DeCooman: Curr. Opin. Solid State Mater. Sci., 2004, vol. 8, pp. 285-303.

14. N. Jin and P. Clayton: Wear, 1997, vol. 202, pp. 202-07.

15. F.G. Caballero, H.K.D.H. Bhadeshia, K.J.A. Mawella, D.G. Jones, and P. Brown: Mater. Sci. Technol., 2001, vol. 17, pp. $512-16$.

16. F.G. Caballero, H.K.D.H. Bhadeshia, K.J.A. Mawella, D.G. Jones, and P. Brown: Mater. Sci. Technol., 2001, vol. 17, pp. 517 22.

17. Z.G. Yang and H.S. Fang: Curr. Opin. Solid State Mater. Sci., 2005, vol. 9, pp. 277-86.

18. H.S. Fang, Z.L. Tan, and B.Z. Bai: J. Iron Steel Res. Int., 2005, vol. 12 , pp. $1-10$

19. F.G. Caballero, M.J. Santofimia, C. Capdevila, C. Garcia-Mateo, and C.G. de Andrés: ISIJ Int., 2006, vol. 46, pp. 1479-88.

20. M.R. Zhang and H.C. Gu: Mater. Sci. Technol., 2007, vol. 23, pp. $970-74$.

21. F.G. Caballero, C.G. Mateo, J. Chao, M.J. Santofimia, C. Capdevila, and C.G. de Andrés: ISIJ Int., 2008, vol. 48, pp. 1256-62.

22. F.G. Caballero, H.K.D.H. Bhadeshia, K.J.A. Mawella, D.G. Jones, and P. Brown: Mater. Sci. Technol., 2002, vol. 18, pp. 279 84.

23. C. Garcia-Mateo, F.G. Caballero, and H.K.D.H. Bhadeshia: ISIJ Int., 2003, vol. 43, pp. 1238-43.

24. P.M. Brown and D.P. Baxter: Materials Science and Technology 2004, TMS, Warrendale, PA, 2004, pp. 433-38.

25. C. Garcia-Mateo, F.G. Caballero, and H.K.D.H. Bhadeshia: ISIJ Int., 2003, vol. 43, pp. 1821-25. 
26. M. Peet, S.S. Babu, M.K. Miller, and H.K.D.H. Bhadeshia: Scripta Mater., 2004, vol. 50, pp. 1277-81.

27. M. Peet, C. Garcia-Mateo, F.G. Caballero, and H.K.D.H. Bhadeshia: Mater. Sci. Technol., 2004, vol. 20, pp. 814-18.

28. K. Goa, L.D. Wang, M. Zhu, J.D. Chen, Y.J. Shi, and M.K. Kang: Acta Metall. Sinica, 2007, vol. 43, pp. 315-20.

29. H.K.D.H. Bhadeshia: Mater. Sci. Technol., 2005, vol. 21, pp. $1293-1302$.

30. H.-S. Yang and H.K.D.H. Bhadeshia: Mater. Sci. Technol., 2008, vol. 24 , pp. $335-42$.

31. F.C. Zhang, T.S. Wang, P. Zhang, C.L. Zhang, B. Lv, M. Zhang, and Y.Z. Zhang: Scripta Mater., 2008, vol. 59, pp. 294 96.

32. L.C. Chang: Wear, 2005, vol. 258, pp. 730-43.

33. C.G. Mateo and F.G. Caballero: ISIJ Int., 2005, vol. 45, pp. $1736-40$.

34. V.T.T. Miihkinen and D.V. Edmonds: Mater. Sci. Technol., 1987, vol. 3 , pp. $432-40$.

35. D.J.C. MacKay: Neural Comput., 1992, vol. 4, pp. 448-72.

36. D.J.C. MacKay: ASHRAE Trans., 1994, vol. 100, pp. 1053-62.

37. H.K.D.H. Bhadeshia: Met. Sci., 1982, vol. 16, pp. 159-65.

38. H.K.D.H. Bhadeshia: Met. Sci., 1981, vol. 15, pp. 175-77.

39. H.K.D.H. Bhadeshia: Met. Sci., 1981, vol. 15, pp. 178-80.

40. H.K.D.H. Bhadeshia: Acta Metall., 1981, vol. 29, pp. 1117-30.

41. H.I. Aaronson, H.A. Domian, and G.M. Pound: TMS-AIME, 1966, vol. 236, pp. 781-96.
42. H.K.D.H. Bhadeshia: Mater. Sci. Eng. A, 2008, vol. 481-482, pp. $36-39$.

43. H.K.D.H. Bhadeshia and D.V. Edmonds: Acta Metall., 1980, vol. 28 , pp. $1265-73$.

44. D.P. Koistinen and R.E. Marburger: Acta Metall., 1959, vol. 7, pp. 59-60.

45. M. Sherif, C. Garcia-Mateo, T. Sourmail, and H.K.D.H. Bhadeshia: Mater. Sci. Technol., 2004, vol. 20, pp. 319-22.

46. M. Mukherjee, T. Bhattacharyya, and S.B. Singh: in Thermomechanical Simulation and Processing of Steels, S.K. Chaudhuri, B.K. Jah, S. Srikant, P.K. Maini, A. Deva, and R. Datta, eds., Allied Publishers Pvt. Ltd., New Delhi, India, 2008, pp. 352-62.

47. NPL: MTDATA: Software, National Physical Laboratory, Teddington, United Kingdom, 2006.

48. H.-S. Yang and H.K.D.H. Bhadeshia: Mater. Sci. Technol., 2007, vol. 23, pp. 556-60.

49. H.M. Rietveld: Acta Crystallogr., 1967, vol. 22, pp. 151-52.

50. H.M. Rietveld: J. Appl. Crystallogr., 1969, vol. 2, pp. 65-71.

51. H.K.D.H. Bhadeshia, S.A. David, J.M. Vitek, and R.W. Reed: Mater. Sci. Technol., 1991, vol. 7, pp. 686-98.

52. P.G. Self, H.K.D.H. Bhadeshia, and W.M. Stobbs: Ultramicroscopy, 1981, vol. 6, pp. 29-40.

53. H.K.D.H. Bhadeshia and A.R. Waugh: Acta Metall., 1982, vol. 30 , pp. $775-84$

54. S.J. Matas and R.F. Hehemann: TMS-AIME, 1961, vol. 221, pp. 179-85. 